\title{
ВЛИЯНИЕ ЛИЗИНГОВЫХ ОТНОШЕНИЙ НА РАЗВИТИЕ ОТЕЧЕСТВЕННОГО АВТОМОБИЛЬНОГО БИЗНЕСА
}

\author{
Н.Н. Жукова \\ Московский гуманитарный университет
}

Аннотация: В статье рассматриваются особенности лизинговых отношений в сфере автомобильного бизнеса. На основании проведенного анализа динамики автомобильного рынка и доли лизинга в корпоративных продажах транспортных средств выявляется их положительное влияние на развитие автомобильного сектора Российской Федерации.

Ключевые слова: лизинг, лизинговые отночения, лизинговый бизнес, рынок автомобилей

\section{INFLUENCE OF LEASING RELATIONSHIPS ON DEVELOPMENT OF DOMESTIC AUTOMOTIVE BUSINESS}

\author{
N.N. Zhukova \\ Moscow University for the Humanities
}

\begin{abstract}
The article discusses the features of leasing relations in the automotive business. Based on the analysis of the dynamics of the automotive market and the share of leasing in corporate sales of vehicles, the positive impact of the leasing instrument on the development of the automotive sector of the Russian Federation was revealed.
\end{abstract}

Keywords: leasing, leasing relations, leasing business, automotive business, automotive market

Развитие и поддержка автомобильного бизнеса является значимым фактором для роста экономики страны. А одним из эффективных механизмов финансирования предпринимательской деятельности на сегодняшний день является лизинг.

Лизинг, или финансовая аренда, определяется как совокупность экономических и правовых отношений, возникающих в связи с реализацией договора лизинга, в том числе приобретением предмета лизинга (Федеральный закон «О финансовой аренде (лизинге)», 1998).

В отличие от многих других видов бизнеса, автомобильный бизнес объединяет в себе сразу несколько различных направлений деятельности:

- прежде всего, это машиностроительная отрасль и производство комплектующих изделий, которые оказывают непосредственное влияние на научно-технический прогресс, дают импульс развитию ряда других отраслей, стимулируют занятость населения, а также являются специфическим показателем жизненного уровня населения;

- рынок автомобилей, представляющий совокупность экономических отношений, благодаря которым происходит взаимодействие субъектов рынка с целью обмена готовых автомобилей на денежные средства или их эквиваленты; 
- транспортные услуги по перевозке людей (пассажирские перевозки) и грузов (грузовые перевозки), деятельность такси и прокат автомобилей;

- работа специального транспорта для городского хозяйства, строительных работ, сельского хозяйства и пр.;

- бизнес по ремонту (автомобильные сервисы) и обслуживанию (продажа автомобильных запчастей, автомойки и пр.) и др.

Российский парк автомобилей, отражающий их общее количество, эксплуатируемых в стране, постоянно развивается. Так, за последние десять лет парк транспортных средств нашей страны вырос более чем на $30 \%$ (рис. 1).

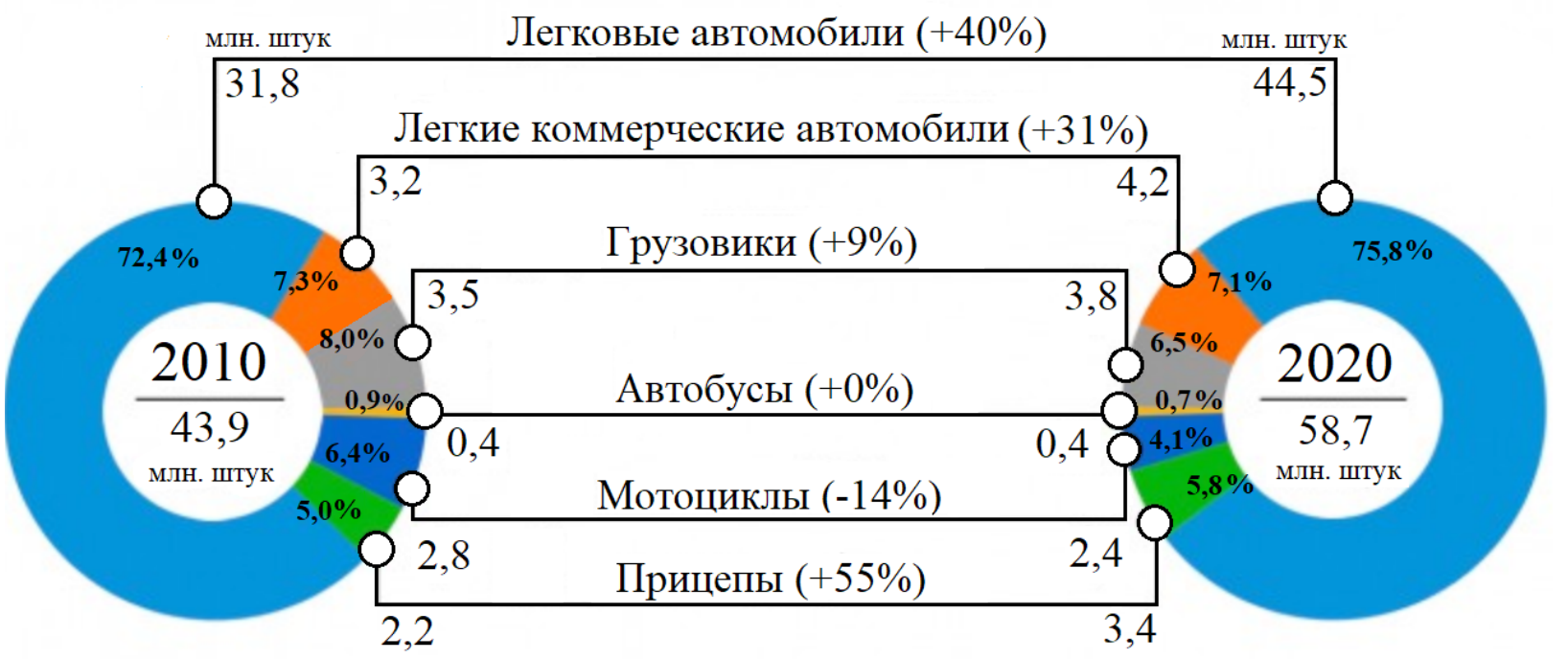

Рисунок 1. Структура российского парка автомобилей на начало 2010 и 2020 г2., млн. шт., \%

Рисунок 1 наглядно показывает, что российский автомобильный рынок характеризуется большой емкостью рынка: если на начало 2010 г. его объем составлял 43,9 млн. единиц, то на начало 2020 г. он достиг уже 58,7 млн. единиц транспортных средств.

Данныйрынокможно разделить на шесть секторов:легковые автомобили, легкий коммерческий транспорт, грузовой транспорт, автобусы, мотоциклы и прицепы.

За прошедшие 10 лет произошло увеличение в большинстве указанных сегментов автопарка. Значительную долю российского автопарка по-прежнему занимают легковые автомобили (более 70\%), количество которых выросло на $40 \%$ - с 31,8 до 44,5 млн. шт. Также значительный прирост показал легковой коммерческий транспорт $(+31 \%)$, который на начало 2020 г. увеличился до 4,2 млн. шт. и составил $7,1 \%$ всего российского автопарка. Парк грузового транспорта показал более низкий рост (+9\%), доля которого снизилась до $6,5 \%$. Наибольший рост показала прицепная техника: количество прицепов увеличилось на $55 \%$ и составило 3,4 млн. шт. 
Научные труды Московского гуманитарного университета

2020 № 6

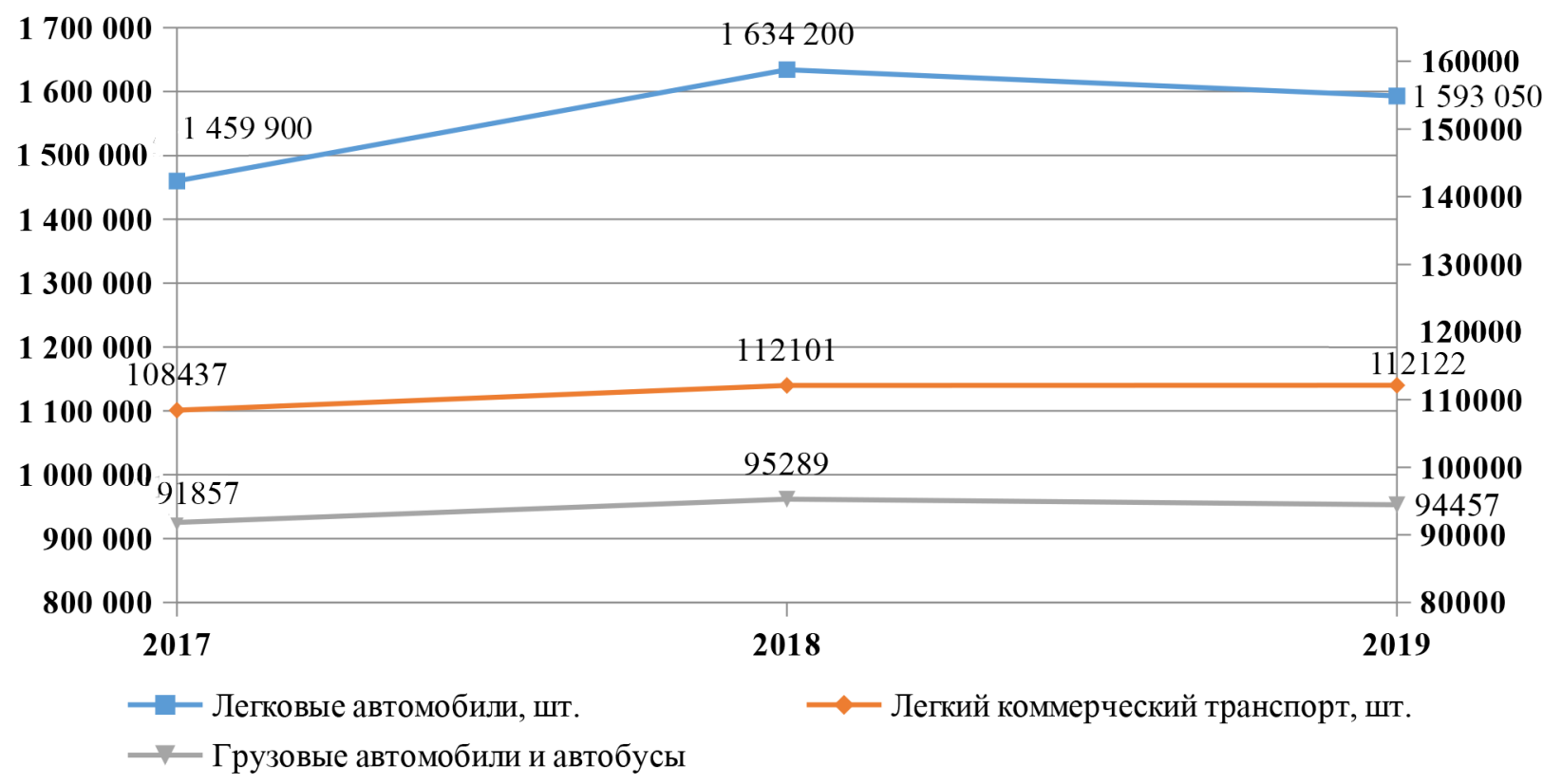

Рисунок 2. Динамика продаж транспортных средств за 2017-2019 г2., ит., \%

Для определения направления развития автомобильного рынка следует провести анализ динамики продаж автомобилей за 2017-2019 гг. (рис. 2).

Анализируя рисунок 2 можно сделать следующие выводы. Стабильный рост продаж автомобилей в течение 2017-2018 гг. прервался незначительным снижением в 2019 г.: продажи легковых автомобилей сократились на 2,49\% или на 41150 ед., грузовых автомобилей и автобусов - на 0,87\% или на 832 ед. Продажи легкового коммерческого транспорта показали незначительный рост (на $0,02 \%$ или на 21 ед.).

Сокращение рынка легкового и легкого коммерческого транспорта было вызвано замедлением экономического роста, снижением цен на нефть, девальвацией рубля и, как следствие, снижением потребительской активности, в том числе снижением активности субъектов малого и среднего бизнеса (Юркина В.И., Щурина С.В., 2020: 169). Негативное влияние на спрос оказало снижение объемов государственной поддержки покупателей, рост цен на автомобили выше уровня инфляции - в среднем на 9\%, а из-за девальвации рубля и роста НДС - до 20\%.

Однако российский рынок автомобилей сохраняет долгосрочный потенциал роста, обусловленный более низкой плотностью автомобильного парка по сравнению с западными странами и его значительным возрастом.

Особенности лизинговых отношений в автомобильном бизнесе определяются спецификой данного вида деятельности и состоят в следующем:

1) обязательная государственная регистрация транспортных средств;

2) высокие неуправляемые внешние риски (дорожные риски, природноклиматические, аварийные риски и др.); 
Научные труды Московского гуманитарного университета

2020 № 6

3) обязательное страхование автотранспортных средств;

4) многокомпонентность лизингового продукта, позволяющая позиционировать его для разных нужд и сегментов потребителей;

5) возможность динамичного изменения лизингового продукта в зависимости от макро- и микроэкономических условий;

6) высокие темпы воспроизводства и износа автотранспортных средств, по сравнению с другими объектами лизинга и др.

Для определения эффекта от влияния лизинговых отношений на развитие рынка автомобилей следует рассмотреть долю транспортных средств, которые были профинансированы через механизм лизинга (рис. 3).

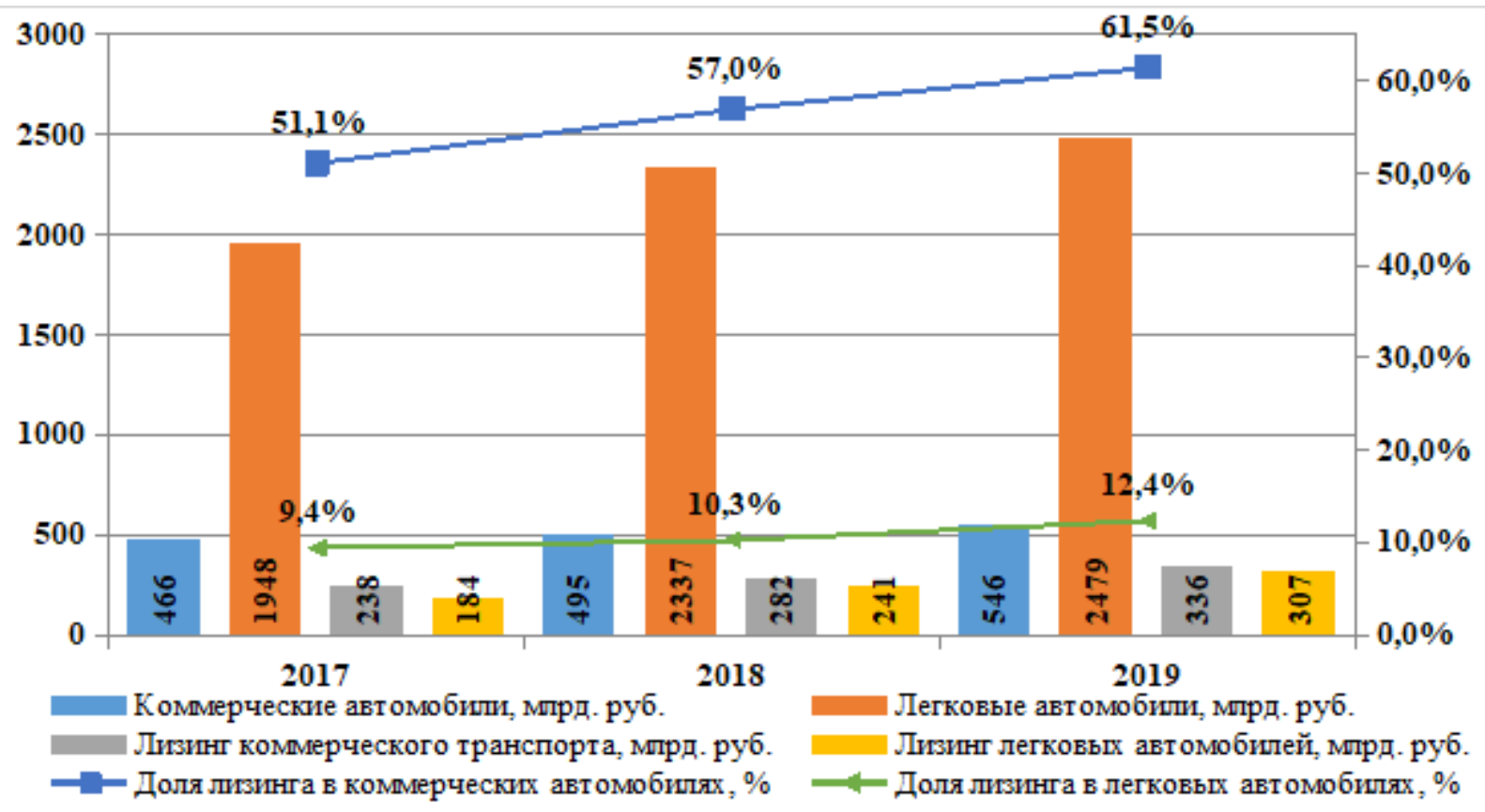

Рисунок 3. Динамика российского рынка автомобилей и доли лизинговых сделок в нем за 2017-2019 г2., млрд. руб., \%

Анализ рисунка 3 демонстрирует больший спрос на лизинговые услуги при приобретении коммерческих автомобилей: с 2017 г. по 2019 г. доля коммерческих автомобилей, приобретенных через лизинговые компании, увеличилась на 10,4\% и составила 61,5\% (или 336 млрд. руб.). Доля лизинга в продажах легковых автомобилей не так существенна, но имеет тенденцию к увеличению. Так, за 2019 г. по сравнению с 2017 г. его доля увеличилась на $3 \%$ и составила 12,4\% (или 307 млрд. руб.). На это, в большей степени, повлияло развитие рынка каршеринга - специфической формы аренды транспортных средств.

Таким образом, сравнивая падение продаж автотранспорта с ростом в их доле сделок, реализованных через лизинг, можно сделать вывод об эффективной 
поддержке данного механизма сферы автомобильного бизнеса. Это связано, в первую очередь, с особенностями лизингового механизма.

Приобретение легкового, легкого коммерческого и грузового транспорта в лизинг - наиболее востребованное направление лизингового финансирования. Данные автомобили используются организациями и предпринимателями независимо от их размеров и видов деятельности, т.к. отличительной особенностью лизинговых отношений является наличие налоговых преимуществ. Так, лизингополучатель может экономить на трех налогах:

1) НДС - лизингополучатель принимает в зачет и снижает налог к уплате в бюджет.

2) Налог на прибыль - расходы по лизингу относятся на себестоимость продукции.

3) Имущественные налоги - предмет лизинга можно учитывать на балансе лизингодателя и не включать в налогооблагаемую базу на протяжении действия договора.

Для лизинговых компаний такое направление лизинговой деятельности является наименее рискованным: автомобиль является высоколиквидным имуществом, вторичный рынок купли-продажи транспорта хорошо развит, автотранспорт регистрируется в государственных органах и пр.

Для государства механизм лизинга важен как средство для ускорения процесса воспроизводств и создания новых рабочих мест, увеличения налоговых поступлений в бюджет за счет активизации производственного процесса, повышения технического уровня производства различных отраслей экономики и др. (Жукова, 2019: 91).

В рамках поддержки отечественных предпринимателей и российского машиностроения Министерством промышлености и торговли реализуются программы льготного лизинга специализированной техники - программы льготного лизинга на грузовой автотранспорт (Постановление Правительства РФ «О предоставлении субсидий из федерального бюджета...», 2017).

Подводя итог всему выше сказанному, можно сделать следующие выводы.

1. На развитие рынка лизинга окажет влияние продолжающееся устаревание автопарка российских компаний (по данныманалитического агентства «Автостат» средний возраст российского автопарка составляет 20 лет).

2. Развитию отрасли машиностроения будут способствовать разработанные правительством программы льготного лизинга, стимулирующие спрос и повышающие конкурентоспособность российской промышленной продукции.

3. Объем лизинга автомобилей продолжит расти, в том числе за счет развития каршеринга и таксомоторных парков.

4. Все это в перспективе окажет стимулирующее влияние на развитие автомобильного бизнеса в стране. 


\section{СПИСОК ЛИТЕРАТУРЫ}

Федеральный закон от 29.10.1998 №164-Ф3 «О финансовой аренде (лизинге)» (ред. от 16.10.2017) // Сборник законодательства Российской Федерации. 02.11.1998. № 44. Ст. 5394.

Постановление Правительства Российской Федерации от 03.05.2017 № 518 «О предоставлении субсидий из федерального бюджета на возмещение потерь в доходах российских лизинговых организаций при предоставлении лизингополучателю скидки по уплате авансового платежа по договорам лизинга строительно-дорожной и (или) коммунальной техники» (ред. от 27.02.2018) // Сборник законодательства Российской Федерации. 03.05.2017. № 20. Ст. 2907.

Жукова Н.Н. (2019) Государственная поддержка развития лизинговых отношений в России//Вестник Национального институтбизнеса:XXIX межвузовская научно-практическая конференция по актуальным вопросам экономики, управления и права. М: МоГУ. № 37. С. 88-94.

Юркина В.И., Щурина С.В. (2020) Проблемы и перспективы развития лизинга в России // Инновационная экономика: перспективы развития и совершенствования. № 1 (43). С. 168-172.

Жукова Наталья Николаевна - студентка третьего курса магистратуры факультета экономики, управления и международных отношений Московского гуманитарного университета. Научный руководитель: доктор экономических наук, профессор Мысаченко В.И. Адрес: 111395, Россия, г. Москва, ул. Юности, д. 5. Тел.: +7 (925) 906-34-06. Эл. адрес: nnzhukova@list.ru

Zhukova Natalya Nikolaevna - third-year master's student at the Faculty of Economics, Management and International Relations of the Moscow University for the Humanities. Scientific adviser: doctor of Economics, Professor Mysachenko V.I. Postal address: 5 Yunosti str., Moscow, 111395, Russian Federation. Tel.: +7 (925) 906-34-06. E-mail: nnzhukova@list.ru

\section{Для цитирования:}

Жукова Н.Н. Влияние лизинговых отношений на развитие отечественного автомобильного бизнеса // Научные труды Московского гуманитарного университета. 2020. №6. C. 108-113. DOI: https://www.doi.org/10.17805/trudy.2020.6.19 